\title{
MICROSTRUCTURE AND ADHESION PROPERTIES POST-ANNEALED METALLIC COATING OF FECRBMNSI ON TUBE AND INTERNAL STRUCTURE COAL-FIRED BOILER
}

\author{
Agung Purniawan, Hengki Irawan and Sigit Tri Wicaksono \\ Departemen of Material and Metallurgy Engineering, Institut Teknologi Sepuluh Nopember (ITS), Sukolilo Surabaya, Indonesia \\ E-Mail: agung_pur@mat-eng.its.ac.id
}

\begin{abstract}
Iron-chrome based metallic coating is generally used to increase the life-time tube and internal structure of coalfired boiler. The most common method used is thermal spray coating. The advantages of this method are simple in application, repair, and low cost. The post-heat treatment coating on metallic coating applied by the thermal spray method can affect to adhesion properties, the number of porosity and microstructure of coating material. The objective of this study is to analyze the influence of post-annealing on the metallic coating FeCrBMnSi applied by Twin Wire Arc-Spraying (TWAS) method on microstructure and adhesion properties which is applied on tube and internal structure of coal-fired boiler. Post-annealing was performed after coating application in vacuum furnace with variety of temperature at $500^{\circ} \mathrm{C}$, $600^{\circ} \mathrm{C}$ and $700^{\circ}$ and holding time about 3 hours. Scanning Electron Microscopy (SEM) and Energy Dispersive X-Ray Spectroscopy (EDS) were used to analyze the morphology of microstructure, the uniformity of the deposit layer, and the percentage of porosity. X- Ray Diffraction (XRD) was used to determine phase formation and composition phase. Then, Pull Off Test was performed for adhesion test that is referred to ASTM D4541. The results shows that increasing postannealed temperature cause microstructure of coating more crystalline, percentage of porosity decreased from $3 \%$ Assprayed to $1,4 \%$ at $700^{\circ} \mathrm{C}$ post-annealing temperature and it has an effect on the adhesion properties of coating which increase up to $25 \%$.
\end{abstract}

Keywords: FeCrBMnSi Coating, Tube and Internal Structure Coal-Fired Boiler, Post-Annealing, Twin wire arc spraying (TWAS).

\section{INTRODUCTION}

High temperature erosion-corrosion and fuel ash corrosion on internal structure and tube boiler are several of the main causes of downtime and point of the principle engineering problems in these installations. Maintenance cost for replacing worn structures and tubes are very high and the downtime associated with unscheduled breakdowns caused by failure of exchanges tubes is a source of lost revenue [2]. There are several approaches which have been used to keep boilers operating for a long time of application (1) Up-grade material which has high chrome content, (2) Weld overlay with inconel material [2] and (3) Thermal Spray Coating which have high chrome and several precipitate agents and self fluxing elements $[1,2]$.

High chromium content improves tribomechanical properties, boron reduces the melting point, silicon increases self-fluxing properties, and iron as the matrix modifies the diffusion rate [5]. Thermal spray coatings are an alternate approach which offer advantages because they allow in-situ recoating of boiler tube an internal structure with the additional ability to repair localized defect inside the boiler. In thermal spray process, the deposited materials are melted by a heat source generated at the nozzle of a spray torch. The heat source can be a fuel gas or an electric arc. After the melt, the atomized material is accelerated by pressure gas against the surface to be coated, reaching it in the melted state [11]. Twin wire arc spraying (TWAS) is one of the thermal spray application method which has several advantages in simplicity of process, low operational cost and high efficiency $[4,6,8]$, but TWAS produce high porosity in coating layer that result a decreasing cohesive and adhesive strength. TWAS method produces coating which has crystalline and amorphous phase that have different type of properties [8]. The adhesion property is the basic requirement that must be fulfilled to make coating continue protect the substrate [8]. The other property should be fulfilled to protect erosion particle is hardness strength coating.

Post heat treatment can be used to further improve the properties of sprayed coatings, such as laser re-melting, shot peening and furnace heat treatment $[1,7]$. The critical consideration about post-heat treatment is possibility of formation thermal growing oxide (TGO) in coating layer and interface between coating layer and substrate during the post-heated process. Bin-You et al. have found that the microstructure and the mechanical properties coating were significantly affected by a post heat treatment especially densification or sintering process in coating layer and its wear behavior. The present study aimed at investigating the effect of post-annealing coating based $\mathrm{Fe}-\mathrm{Cr}$ that is applied by twin wire arc spraying (TWAS) on the microstructure and adhesion properties for increasing the life time of coating layer to protect internal structures and tube coal fired boiler.

\section{MATERIAL AND METHODS}

\section{Material substrate and coating}

Commercially available $\mathrm{Fe}-\mathrm{Cr}$ based wire metallic coating with a diameter $1,6 \mathrm{~mm}$ which has chemical composition (wt.\%) 64.6 Fe, 28.0 Cr, 3.7 B, 2.0 $\mathrm{Mn}$ and 1.7 Si was used to produce metallic coating on the substrate. The metallic coatings were sprayed onto the 
carbon steel substrate (size: $50 \times 40 \times 3 \mathrm{~mm}$ ) which has chemical composition (wt.\%) $0.25 \mathrm{maxC}, 0.27 \mathrm{Mn}$, $0.035 \mathrm{maxP}, 0.035 \mathrm{maxS}, 0.1 \mathrm{minSi}$, Balanced Fe. Prior to coating, the substrates were blasted with 24 mesh brown alumina oxide by 5 bar compressed air. The distance blasting gun to the substrate $\pm 150 \mathrm{~mm}$. Measuring the roughness substrate uses test-tex press $\mathrm{O}$-film which refers to ASTM Standard D4417-03. The blasting results onto the substrate are about 75-80 $\mu \mathrm{m}$. After the substrate was grit-blasted, the substrate was cleaned by degreased acetone then dried by compressed air.

\section{Coating applications}

The coatings were sprayed onto the substrate by TAFA model arc spraying system which has suitable nozzle to twin wire input under the optimized spray parameter. The parameter was as follows: arc voltage, 32 Volt; arc current, $150 \mathrm{~A}$; Air pressure, 65 Psi; spray distance, $100 \mathrm{~mm}$. the samples were coated until thickness being about $1000 \mu \mathrm{m}$. During spraying, the samples were not cooled by compressed air. After spraying, the coating thickness should be measured by micrometer screw gauge to ensure uniformity of coating thickness.

\section{Glass transition temperature measurement}

Before the coating was post-annealed, the coating layer had been measured its glass transition temperature. Measuring the glass transition temperature is to decide experiment post-annealing temperature, then to study the phenomena around this temperature about the microstructure of coating. The coating was removed from the substrate, and pounded by a mortar into powder (about $20 \mathrm{mg}$ ) for DSC measurement. The phase transformation characteristic was investigated by differential scanning calorimeter (DSC, Mettler Start SW 10.00) in continuous heating mode at a rate $20^{\circ} \mathrm{C} / \mathrm{min}$ from room temperature to $900^{\circ} \mathrm{C}$. The result of DSC trace of FeCrBMnSi as-sprayed can be seen on Figure-1. From DSC pattern can be measured the glass transition temperature.

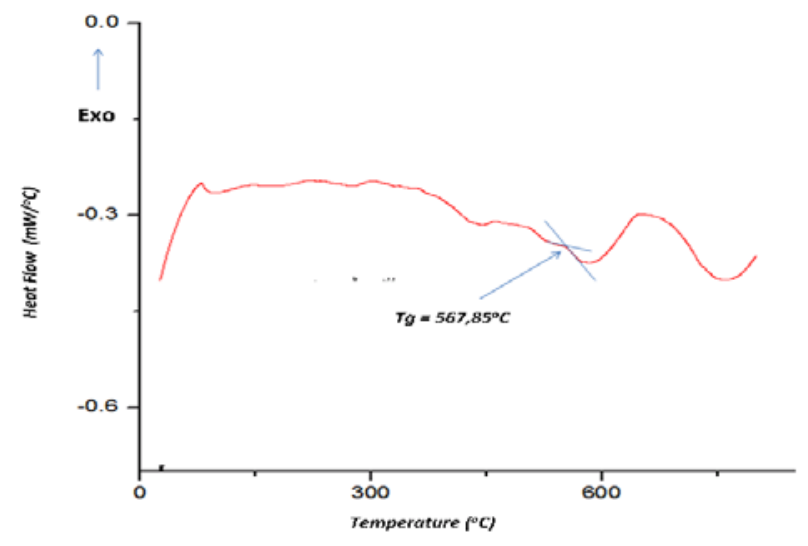

Figure-1. Typical DSC trace of FeCrBMnSi coating.

\section{Vacuum post-annealing}

After glass transition temperature was known from DSC pattern, the coating were post-annealed in a horizontal vacuum furnace at temperature $500^{\circ} \mathrm{C}, 600^{\circ} \mathrm{C}$ and $700^{\circ} \mathrm{C}$ for 3 hour. During the post-annealing, Argon was injected around 2,7 slpm until temperature reach at $200^{\circ} \mathrm{C}$, then the specimens were cooled in furnace until atmospheric temperature. To avoid peeling off of the coating from the substrate due to larger thermal stresses, the heating and cooling of all sample were carried out in the furnace with low heating and cooling rate [3], so the heating and cooling rate in vacuum furnace was $10 \mathrm{~K} / \mathrm{min}$.

\section{Coating characterization}

The microstructure of the coatings were examined by using scanning electron microscopy (SEM) equipped to X-ray energy dispersive spectroscopy (EDS). Samples for microscopic examination were prepared by standard metallographic technique. Porosity was measured on SEM Images with the help of image analysis. An average value porosity was taken from 10 locations of each coating the cross-section of coatings. The phase composition of coatings were characterized by the X-ray diffraction (XRD) (PANalytical Xpert-Pro) using $\mathrm{Cu} \mathrm{k \alpha}$ target at $40 \mathrm{kV}$ and $30 \mathrm{~mA}$. Bond testing of coating was conducted using the ASTM D4541 standard pull off method. The test was then conducted on an adhesive pull off tester (PosiTest AT-M manual). Loctite 907 hysol glue was used as bonding adhesive material between coating and dolly. Bond strength of coating were averaged over 10 specimens. The additional micro-hardness test ( $\left.\mathrm{Hv}{ }_{500 \mathrm{gf}}\right)$ was performed to complete the result of experiment.

\section{RESULT AND DISCUSSION}

Figure-2 shows the typical cross-sectional microstructure SEM images of the as-spray and annealed coatings. The coating is consist of numerous flattened lamellae parallel to the substrate, indicating that most of sprayed droplets were in molten or semi-molten state as they impacted on the substrate. All of coating had a lamellar structure, some pores and half-melted/ un-melted particles. The microstructure of the coating is divided to be three phase : the light metal lamellae (Point 1), the grey lamellae (Point 2), and half-melted particle (Point 3). The result of EDS of as sprayed coating (as shown in table 1) indicated that the light metal lamellae is Fe-rich phase and the EDS mapping (Figure-3) shows borides distribute in the metal matrix in these lamellae. The distribution of borides were not homogeneous in the coatings, for that some splats consist of lots of hard particles. The grey lamellae (Point 2) in coating layer could be the remained borides and oxide content. The micro-hardness measurement showed that these gray lamellae were highest hard, with the micro-hardness about $1340 \mathrm{Hv}_{500 \mathrm{~g}}$. These borides were not completely dissolved in molten Fe-Matrix during spraying or the primary crystallized borides in droplets with high $\mathrm{B}$ and $\mathrm{Cr}$ content [1]. Point 3 is identified as half melted particle which were occasionally identified by their white spots appearance morphology. Half melted indicates that the particle's temperature was higher enough [5]. After annealing treatment, metal oxide phase in dark gray color (Point 2), half-melted particles (point 3) and original boundaries between lamellae became more unclear with increasing post- annealing temperature. From Figure-2 indicates that densification or sintering process has occurred so that the porosity of the coating layers decreased with increasing annealing temperature. 

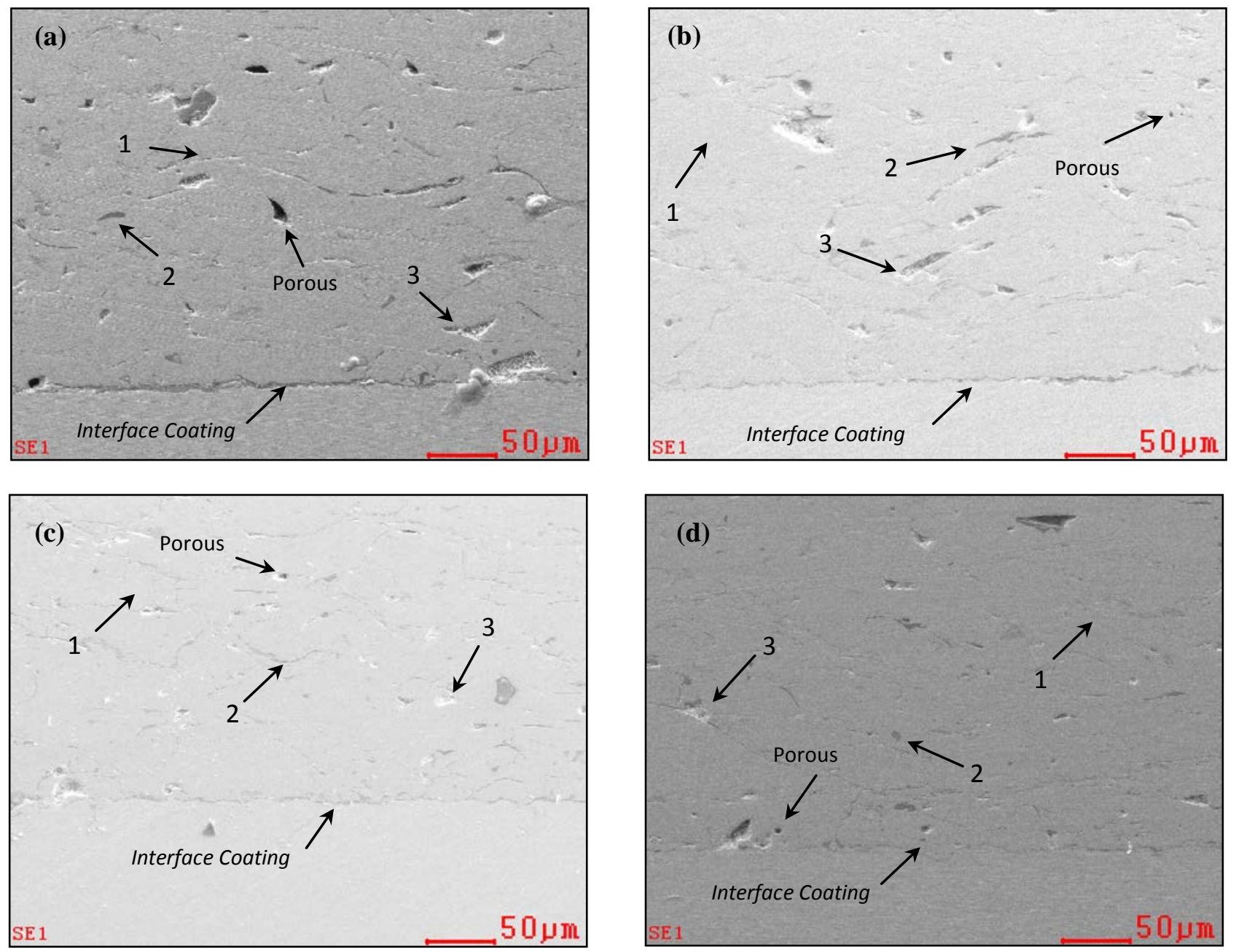

Figure- 2. SEM image of cross-sectional microstructure: (a) as-sprayed coating, (b) coating annealed $500^{\circ} \mathrm{C}$, (c) coating annealed $600^{\circ} \mathrm{C}$, and (d) coating annealed $700^{\circ} \mathrm{C}$.

The as-sprayed coating has the highest porosity of approximately $3.76 \%$. After annealing, the porosity of the coating has decreased to about $1.47 \%$. Figure- 4 shows percentage of porosity as-sprayed coating and the annealed coatings. There has two possible phenomenon have occurred to explain this condition. The first reason is self fluxing reaction. The self fluxing reaction has occurred because of boron and silicon content in Fe-based alloy. The partial melted/ un-melted particle involve in semi-or un-molten borides, if in the melting states during thermal spray process, it could be easy to create the formation of amorphous phase and then produce solid solution strengthening in Fe-matrix (e.g. $\alpha-\mathrm{Fe}$ ) solution [10].

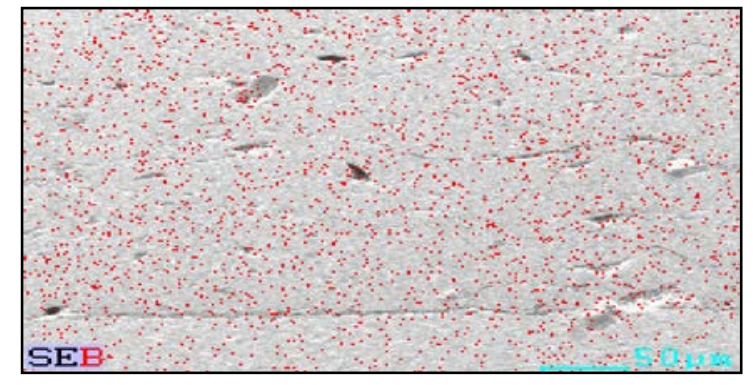

Figure. 3. EDS Mapping of element boron in as-sprayed coating layer.
Table-1. The composition of different point in the assprayed coating (wt.\%).

\begin{tabular}{|c|c|c|c|c|c|c|}
\hline No & Fe & Cr & B & Mn & Si & O \\
\hline 1 & 60.53 & 28.28 & 01.25 & 05.03 & 02.43 & 02.48 \\
\hline 2 & 44.29 & 31.43 & 02.19 & 07.54 & 03.55 & 11.00 \\
\hline 3 & 50.16 & 33.49 & 01.15 & 04.28 & 07.40 & 03.54 \\
\hline
\end{tabular}

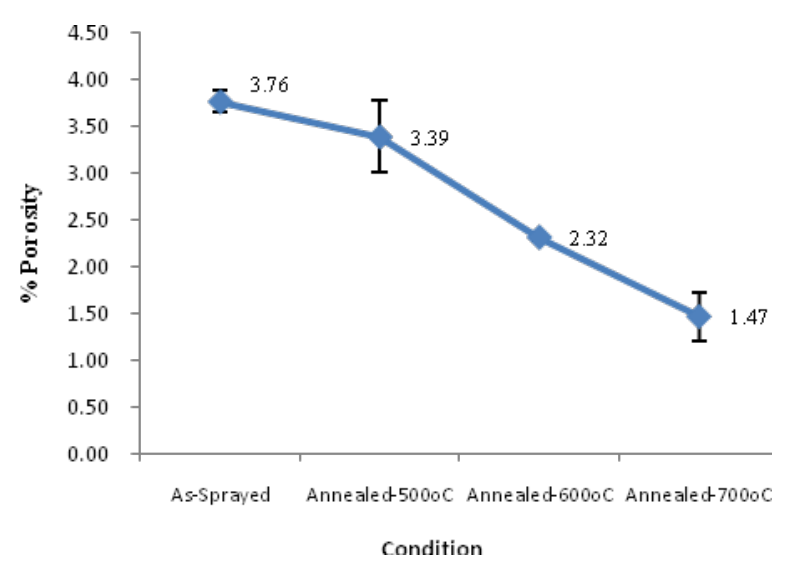

Figure-4. Porosity percentage of as sprayed and annealed coatings. 
The characteristic of element boron can reduce melting temperature its alloy so as the densification process/ solid state sintering (at $0.35-0.5$ temperature melting) can occur at temperature that is not too high. The effect of this reaction for the partial melted/un-melted particle is not very helpful for decreasing its porosity due to heat treatment at temperature below its own glass transition temperature ( $\mathrm{Tg})$. It means that there is not enough driving force to re-start self fluxing reaction at such low annealing temperature [10]. This statement can be cleared by Figure- 4 that percentage of porosity decreased only few points from 3.76 to 3.39 when the coating was annealed lower than temperature glass $(\mathrm{Tg})$. Another reason is related to the phase transformation. The precipitation of different new phase and different in the degree of the growth or expansion of some phase during the heat treatment may result in the variation of porosity [12].

Figure-5 demonstrates the XRD patterns of the as-sprayed and the annealed coating. As shown in Figure5 , a sharp shape at X-ray diffraction angles of about $45^{\circ}$ can be observed in the as-sprayed coating, indicating the crystalline phase had been formed in the coating. From the pattern, the coating was mainly composed of $\mathrm{Fe}-\mathrm{Cr}$ alloy and $\left(\mathrm{Fe}_{9} \mathrm{~B}\right)_{0.2}$ hard phase with a fraction of $\mathrm{Fe}_{2} \mathrm{MnSi}$. After post-annealing at $500^{\circ} \mathrm{C}, 600^{\circ} \mathrm{C}$ and $700^{\circ} \mathrm{C}$ the peaks become sharper and shift to the angle increasing direction (reducing d-spacing). This is due to the crystallization process had still occurred. After post-annealed the intensity of the hard phase and $\mathrm{Fe}-\mathrm{Cr}$ based coating increase enough significantly and FWHM decreased, it means the phase of coating more crystalline. Refers to Scherer formula, the calculated grain size increases as the FWHM (full-width half maximum) decreases; the measured result shows that the average gain size of the assprayed, $500^{\circ} \mathrm{C}, 600^{\circ} \mathrm{C}$, and $700^{\circ} \mathrm{C}$ were about $40 \mathrm{~nm}, 41$ $\mathrm{nm}, 43 \mathrm{~nm}$ and $47 \mathrm{~nm}$.

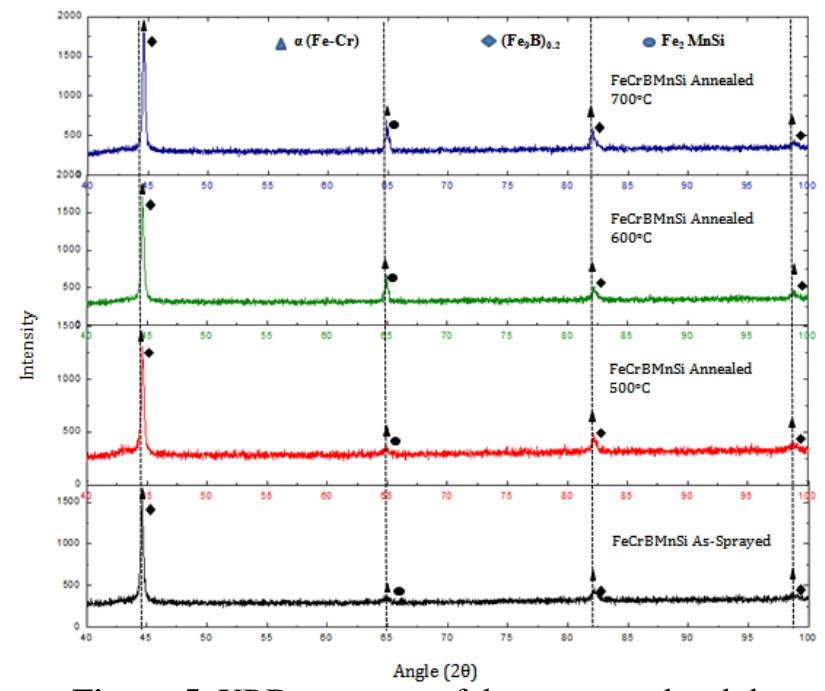

Figure-5. XRD spectrum of the as-sprayed and the annealed coatings.

Figure-6 shows the results of pull off test specimens. As shown in Figure- 6, the failure of the pulloff test results is dominant cohesive bond failure. There are two reasons why the coating has good adhesion bonding. The first, better surface preparation to create clean blasting grit cause better mechanical interlock between coating layer and substrate and vacuum postannealing procedure cause no formation thermal growing oxide (TGO) in interface layer during the post-annealing process, it can be seen in Figure- 2 that the interface layer is very thin in as-sprayed coating and the post-annealed coatings. The second, the diffusion phenomena between elements of coating and substrates had occurred. The diffusion phenomena each element in coating is very helpful in increasing adhesive strength coating, and the rate of diffusion can be increased by increasing postannealing temperature $[9,10]$. The diffusion phenomena in this coating can be clarified in Figure-7 which shows the EDS measurement in area near interface as-sprayed coating.

The cohesive strength of the coating depend on several things such as percentage of porosity, cracks, TGO in coating layer, precipitate in a base metal matrix of coating [10]. According on Figure 2, the percentage of porosity is the main cause cohesive failure in coating layer than the other causes. Refers to Figure-4, it is clear that a significant decrease of the porosities in coating layer after increasing temperature post-annealing. It can be compared to the magnitude of bonding strength from the pull off test result as shown in Figure-8. The other causes such as cracks are not shown in coating layer in figure 2 and the formation of precipitate in metal matrix coating does not give a clear relation to cohesive failure in coating layer. The formation of boron precipitate in Fe-matrix which is shown at Figure-3 in coating layer creates coating hardness become increase and the increasing of post annealing temperature effects on increasing coating hardness because of the decomposition of the remain amorphous phase into nanocrystalline phase [1]. The microhardness test result of as-sprayed and annealed coating can be seen in Figure-9.

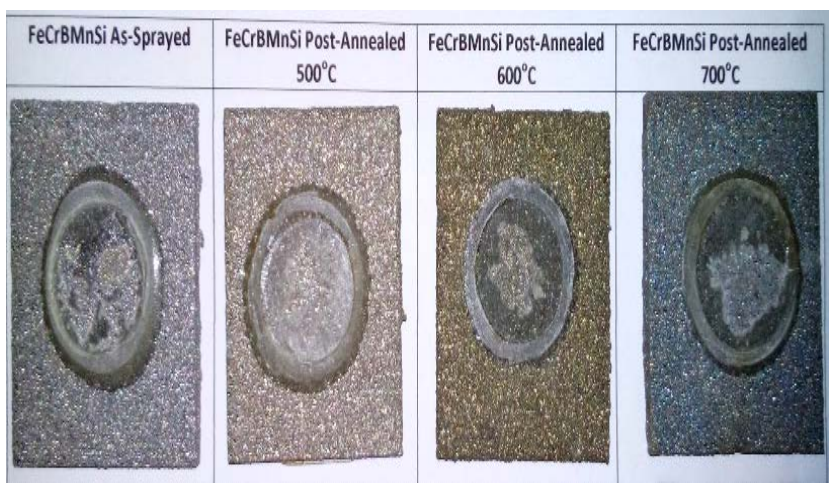

Figure-6. The results of pull off test specimens as-sprayed and post-annealed coatings. 


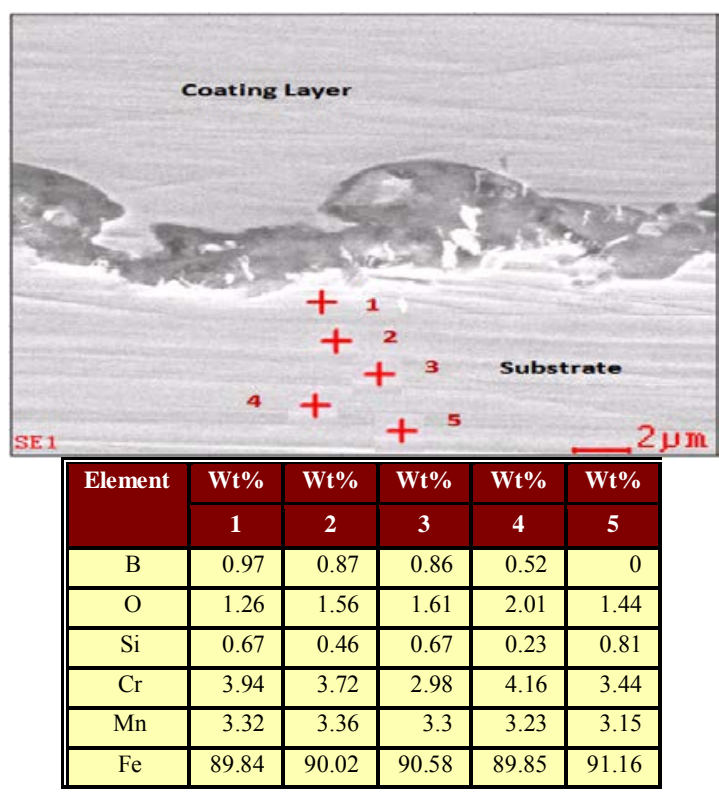

Figure-7. EDS measurement element of post-annealed $500^{\circ} \mathrm{C}$ coating in area near interface.

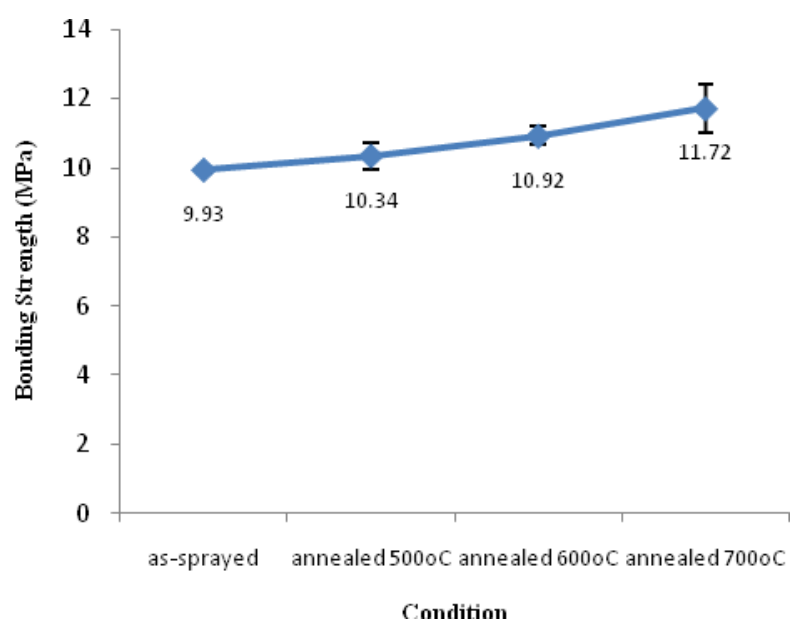

Figure-8. Bonding strength as-sprayed and post-annealing coatings.

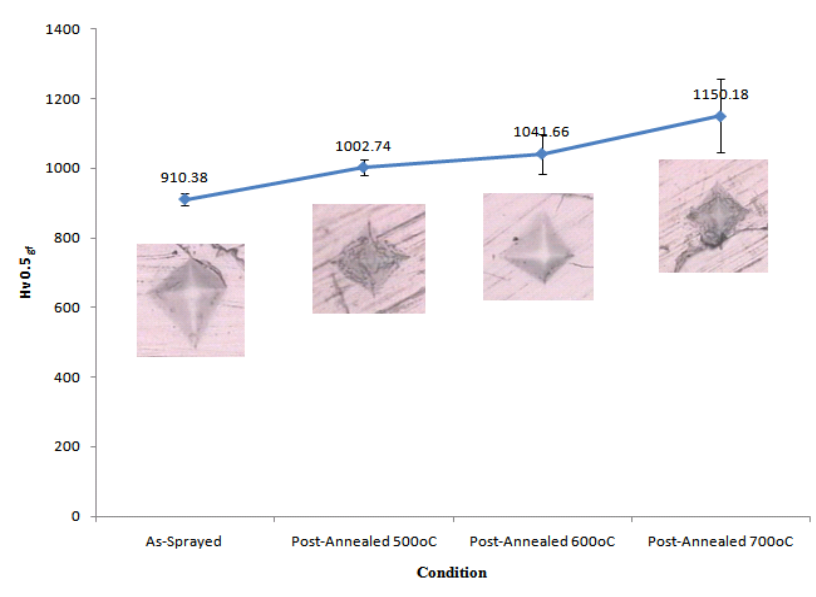

Figure-9. Microhardness Vickers $\left(\mathrm{Hv}_{0.5}\right)$ as-sprayed and post-annealed coatings.

\section{CONCLUSIONS}

In the present study, effect of post-annealing on the microstructure and adhesion properties of $\mathrm{FeCrBMnSi}$ coating which is applied by twin wire arc spraying (TWAS) were investigated. The obtained results are summarized as follows :

1. As-sprayed and post-annealing coatings show a typical lamellar structure. Crystalline phase and remain amorphous phase $\left(\alpha-(\mathrm{Fe}-\mathrm{Cr}),\left(\mathrm{Fe}_{9} \mathrm{~B}\right)_{0.2}\right.$, $\mathrm{Fe}_{2} \mathrm{MnSi}$, and oxide could be identified in the coatings.

2. The as-sprayed coating layer has been formed crystalline phase, but the crystallization and densification still occurs at temperature $700^{\circ} \mathrm{C}$. As the post-annealing temperature increase, the coating shows a reduction in porosity and a significant enough increase in the cohesive strength.

3. The diffusion of element coating has started when the coating is applied and still occurs at postannealing temperature, then the coating layer has better adhesive strength.

4. The formation of precipitate in coating layer creates coating hardness become increase and the increasing of post annealing temperature effects on increasing coating hardness, then the combination between better adhesion properties and high hardness makes the lifetime of coating layer be longer so that can continue to protect tube and internal structure coal-fired boiler.

\section{ACKNOWLEDGMENTS}

The authors wish to thank the Department of Material and Metallurgical Engineering Faculty of Industrial Engineering, Institut Teknologi Sepuluh Nopember- Surabaya (ITS-Surabaya) and Mr. Larasanto as Operational Director of PT. Cipta Agung (A Company that specialized in Industrial Coating Services) for its support.

\section{REFERENCES}

[1] Bin-you Fu, Ding-yong He, Li-dong Zhao. 2009. Effect of heat treatment on the microstructure and mechanical properties of Fe-based amorphous coatings.Journal of Alloys and Compounds.480: 422427.

[2] Branagan D.J, Breitsameter. M, Meacham B.E, Belashchenko.V.2005.High Performance Nanoscale Composite Coatings For Boiler Applications. Institute of Nanomaterial Research and Development The Nanosteel Company.

[3] Chaoping Jiang, Yazhe Xing, Jianmin Hao, Xuding Song. 2013. Effect of Heat-treatment on Crystallization and Wear Property of Plasma Sprayed 
Fe-Based Amorphous Coatings. Journal of Wuhan University of Technology-Mater.Sci.Ed.

[4] Chen Yongxiong, Liang Xiubing, Wei Shicheng, Liu Yan, Xu Binshi. 2009. Heat treatment induced intermetallic phase transition of arc-sprayed coating prepared by the wire combination of aluminiumcathode and steel-anode. Journal Applied Surface Science 255: 8299-8304.

[5] Gil Linda, Rodriquez Maria. 2011. Wear resistance of post heat treated HVOF coatings based on cermetnickel based alloys mixture. $9^{\text {th }}$ Latin American and Caribbean Conference for engineering and technology. WE1-1

[6] Lin Jinran, Wang Zehua, Lin Pinghua, Cheng Jiangbo, Zhang Xin, Hong Sheng. 2014. Microstructure and cavitation erosion behavior of FeNiCrBSiNbW Coating prepared by twin wires arc spraying process. Journal Surface \& Coating Technology. 240: 432-436.

[7] Lin Jinran, Wang Zehua, Lin Pinghua, Cheng Jiangbo, Zhang Xin, Hong Sheng. 2015. Effect of post annealing on the microstructure, mechanical properties and cavitation erosion behavior of arcsprayed FeNiCrBSiNbW coatings. Journal Material and Design 65: 1035-1040.

[8] Lin. J.R, Wang Z.H, Lin P.H, Cheng J.B, Zheng X, Hong S. 2014. Effect of crystalisation on electrochemical properties of arc sprayed FeNiCrBSiNbW coatings. Journal Surface Engineering 30. 683-687.

[9] Liu Guang, An Yulong, Chen Jianmin, Hou Guoliang, Chen Jie. 2012. Influence of heat treatment on microstructure and sliding wear of thermally sprayed Fe-Based Metallic Glass Coating. Tribol Lett 46: 131138.

[10] Liu Wu-Han, Shieu Fuh-Sheng, Hsia Wei-Tien. 2014. Enhancement of wear and corrosion resistance of iron-based hard coatings deposited by high-velocity oxygen fuel (HVOF) thermal spraying. Journal Surface \& Coating Technology 249: 24-41.

[11] Sa Brito V.R.S, Bastos I.N, Costa H.R.M. 2012. Corrosion resitance and characterization of metallic coatings deposited by thermal spray on carbon steel. Journal Material and Design 41: 282-288.

[12]Zheng.Z.B, Zheng Y.G, Sun W.H, Wang J.Q. 2015. Effect of heat treatment on the structure, cavitation erosion and erosion-corrosion behavior of Fe-based amorphous coatings. Journal Tribology International. 